\title{
Development of the Activity of Learning Geometric Concepts in Younger Adolescents: Social and Cultural Communication
}

\author{
Nataliya Georgievna Podaeva
}

Bunin Yelets State University, Head of the Department of Applied Mathematics and Informatics, Doctor of Sciences Professor, 399770 Gagarin st., 26, Elets, Lipetsk region; podaeva@mail.ru

\section{Mihail Valer'evich Podaev}

Bunin Yelets State University, Associate professor, Department of Mathematics and Methods of Teaching Mathematics Ph.D., 399770 Gagarin st., 26, Elets, Lipetsk region; podaev86@rambler.ru

\author{
Doi:10.5901/mjss.2015.v6n6p503
}

\section{Abstract}

Present article is written in the framework of socially- and culturally-oriented mathematics teaching, developed by the authors. The authors theoretically validate the technology of teaching geometry to younger adolescents, which is oriented towards learning the value content of geometric concepts. From the positions of social and cultural approach the article analyses communication - a phase of value learning cycle. Communication is a development of understanding and means of operating geometric concepts. There are several stages of communication; their content is defined by the structure of the activity component of geometric concepts, which includes object-oriented actions, as well as real learning and formal operations. Based on the theoretical framework of communication principles, during a developmental experiment the authors created an academic complex for the students of 5-6th grades in middle schools. Logical component of communication has three stages during the experimental learning. The content of these stages is defined by the classification of the learned geometric concepts based on the level of thought process operations (real, formal and integral). The article describes an algorithm for the organization of geometric concepts value content learning during communication process. It also addresses the stages of development of spatial and logical communication components on the example of teaching geometry to younger adolescents. The following hypothesis has been theoretically validated and experimentally confirmed: social and communicative processes efficiency in the situation of geometry learning in younger adolescents depends on multiple factors, such as realization of psychological and didactic patterns of awareness, understanding and generalizing activity content and process; gradual development of the activity of learning geometric concepts value content; gradual development of an integral psychological structure "image - representation - pre-concept - concept - system of concepts"; gradual development of geometric concepts activity components - object-oriented actions, real cognitive operations, formal operations.

Keywords: social and cultural approach; teaching geometry to younger adolescents; communication; value content of geometric concepts; integral operations.

\section{Introduction}

According to the results of PISA international monitoring, Russia was on 34th position of 65 in the general rating in 2012. In 2013 "... it was still impossible to move forward" (Gerasimova, E. 2013). Let us repeat that the actual object of monitoring is the level of students' thinking, IQ, intellectual level, which is controlled through the diagnostics of the quality of written and oral speech, development level of mathematic tasks solving skills, etc. In 2013 the expertise also included exploring the tendencies of mathematics education development. National Study of Education Quality (NSEQ-2014), conducted in 2014, revealed the tendency of mathematics education decrease from $5^{\text {th }}$ to $7^{\text {th }}$ grade, which was accompanied by the general decrease of interest towards mathematics as a school subject.

Analysis of the reasons and possible solutions for this situation revealed two opposite points of view in Russian pedagogic society. The most radical advocates of the present and necessary modernization are practically ready to destroy the current educational system in order to support new tendencies. These reformers talk about the retardation of "Soviet education" and consider it necessary to "renew school educational program in math by "adapting" it towards "present time requirements", make it "basic" for all and extended for the advanced" (Savitskaya, N. 2014). On the other hand, the supporters of traditional approach insist on returning to the "old Soviet education" - to preserving everything valuable that was collected by the efforts of scientists, teachers and methodologists. 
In search of the answer where to put a comma in the sentence "break not modernize", let us refer to the new educational standards of secondary (complete) education. As far as subjects learning programs are concerned, the standards change the whole paradigm of school education: informational and translational school is transformed in the activity school (Podaeva, N.G. (2012)). "Amount - oral translation - cramming" is an inherited utopia of learning the collected "iceberg" of human culture and knowledge. Activity paradigm, on the other hand, focuses on personality selfrealization in this culture and this knowledge and on personality socialization.

Accepting this point of view allowed us to develop a framework of socially- and culturally-oriented mathematic education (Podaeva, N.G. (2012)). Constructing object in our study is the learning activity, which allows attributing means of acting and understanding required for the development of axiological attitude towards mathematics in the geometry learning-teaching situation of younger adolescents.

Social and cultural (culturally-axiological) approach allows defining mathematic education as a form of human culture, oriented on translating and learning accumulated experience and knowledge as cultural values carries and on social and cultural development of the students through mathematics. It provides the possibility of students' efficient social activity, development of their culture, skills and needs in social interactions, expanding summary of which is social strengthening and complication of social culture, while their decreasing summary is social entropy and road to chaos and degradation.

In the social and cultural educational framework, which is developed by the scientific school of V.I. Dobrenkov, V.I. Nechaev, M.K. Petrov (Dobrenkov, V.I., Nechaev, V.Ya. (2003)) and others, cognitive activity is described as a system, the components of which are simultaneously considered the stages of the cycle of cultural values learning and the learning activity dynamics - axiological orientation, impulse, communication, adaptation and creation (pic. 1). The central basis is the theory of integrative expansion of social and cultural mechanisms and cognitive functions providing them.

Axiological attitude as the "accepting or denying the object" (Dobrenkov, V.I., Nechaev, V.Ya. (2003)) occurs on every stage of this cycle but it becomes a cultural value only after passing through all of the cycle phases.

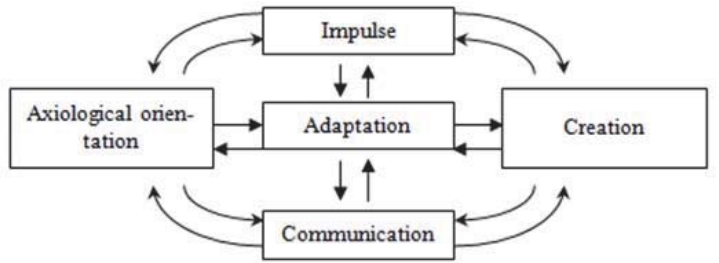

Figure 1. The model of axiological learning dynamics.

\section{Methods}

\subsection{Social and cultural communication in teaching geometry to younger adolescents}

In line with social and cultural educational framework we will describe the content of communication stage, which is a complex system of activity mechanisms and a feedback component in the dynamics of value learning in the learningteaching situation.

It is impossible to debate the significance of communicative aspect in education, its participation in translating cultural values and providing generations succession, which is the most important function of social life reproduction. However, the questions of the development of communication and of the process of understanding, directly related to it, are currently only superficially described when it comes to mathematic education. The study of social and communicative processes in learning-teaching situation and their part in providing axiological attitude towards mathematics is not being set as a separate task in present pedagogic theory and practice. Teachers do not usually have a method for starting and maintaining meaningful problematic communication during math lessons.

Studying the communicative process as a phenomenon, it is important to note that in the activity paradigm communication is viewed as a combined activity of communicants, during which a joint understanding of objects and 
actions with them are created. According to the activity paradigm (G.P. Schedrovitskiy (Schedrovitskiy, G.P. )), we can refer to communication-translation (repetition) of the activity of exploring the material.

Communication, translation in sociologic studies is defined as a process of semantic information (meanings and contents) movement. Social and communicational activity expresses internal unity of objectifying and de-objectifying interactions. This characteristic is viewed as a basis of communicative process: communication is a directed connection between the subject and the surrounding environment with objectifying ("packing", encoding the information) and deobjectifying (decoding, recognizing the information). The main goal of communicative process is to provide experiencing (emotional attitude) and understanding (reflexive attitude) of axiological positions. Because of this, communication can be defined as translation - objectifying and de-objectifying - of not only the information, but of its meaning and content (axiological content) with symbols. The problem is that when it comes to mathematic education, the main principle is still "learn-all" - "amount - oral translation - cramming" of the given amount of information (Podaeva, N.G. (2012)), which does not pass the stage of legitimation - is not being understood and, consequently, is not being learned and used, i.e. does not transform into knowledge.

Communication development vector can be presented as the one combining three surfaces (coordinates). The first is the movement in the plane of socially- and culturally-oriented mathematic education. Communication is defined as a cycle phase, a feedback component in the suggested dynamics of cultural learning of the values (which are carried by mathematic categories, objects and methods) (Podaeva, N.G. (2012)), (Podaeva, N.G., Podaev, M.V. (2013)).

The second coordinate describes the "movement" in psychological and didactic context. The are several levels of proficiency (understanding, learning and using the material), which create an integral system of gradual development of mathematic knowledge and skills learning, as well as cultural abilities development (Podaeva, N.G. (2012)). This refers to the acquisition of cognitive experience, of the skills development as cognitive actions, which are operations derivative from object-oriented actions; this means that these levels can also be described as the cognitive process functions. Conceptual hypothesis contains the suggestion that the efficiency of social and communicative processes in the situation of learning geometry, which provide reflexive and emotional attitude towards mathematic values (understanding and experiencing the axiological positions), is defined by a number of factors. The central position among these factors is taken by the realization of psychological and didactic tasks of awareness, understanding and generalizing activity content and process. The criterion of awareness is a well-developed "implicit knowledge"- an ability to "interpret" the signs and their combinations in the sign and symbolic system, an ability to attribute a perceived object to a certain object category, a skill to obtain the concepts - establishing a connection between a word and an image, differentiating the capacity and the content of the concept, imagining words representations, creating a precept (perception image) and correctly validating the actions; "present awareness" (A.N. Leontyev) - an ability to reflect and understand the content of an educational subject as a goal of one's activity.

The third coordinate is the movement in the plane of exploring the activity component of geometric concepts, of their axiological content (meaning).

\subsection{The specificity of geometric concepts development}

It is necessary to specify that psychodidactics separates two levels of knowledge acquisition - level of representations and level of concepts (verbally-logical level). On the level of representations object characteristics are present but in limited amount, they are undivided, not differentiated and there is no knowledge of their interconnections. Conceptual thinking, on the other hand, is always the knowledge of a certain collection of object characteristics. Moreover, conceptual thinking is a system: learning each single concept is defined by the nature of its interaction with other concepts. L.S. Vygotskiy stated: "The nature of every single concept already implies a certain system of concepts, without which it cannot exist" (Vygotskiy, L.S. (1982)). The process of concepts learning is traditionally considered especially significant in the analysis of school geometry (V.A. Gusev, 2003, 2010, 2004), E.N. Kabanova-Meller (Kabanova-Meller, E.N. (1962)), M.V. Ryzhik (Ryzhik, V. (2005)), N.S. Podhodova (Podhodova, N.S. (1999)), (Gusev, V.A., Orlov, V.V., Panchishina, V.A. et al. (Ed. Gusev, V.A.) (2004)), G.I. Sarantsev (Sarantsev, G.I. (2000)), O.V. Kholodnaya (Kholodnaya, M.A. (2002)), A.Ya. Tsukar (Tsukar, A.Ya. (1999)), I.S. Yakimanskaya (Yakimnaskaya, I.S. (1980)), M.V. Podaev and others).

The problem with traditional geometry teaching is that a concept is viewed from the positions of logic ("from the definition") and is interpreted as a reflection of significant characteristics. Troubles, which occur during verbal ("from the definition") description of geometric concepts, can be explained by the fact that in this approach a number of questions remain unanswered. How do concepts develop in humans, how are they related to the stored images and therefore to their experience? Which image would students create in regard to their experience - how adequately would they decode the geometric discourse and "translate" it to their own language? How well do these images, created by the students, 
correspond with geometric concepts? The answers to these questions are provided by psychological explanation, which analyses a concept as a multilevel hierarchic structure, which includes the images of various levels of generality (L.M. Vekker (Gusev, V.A., Orlov, V.V., Panchishina, V.A. et al. (Ed. Gusev, V.A.) (2004))).

Let us repeat that the main categories of communicative process are: a code - algorithms, rules of the message content translation; encoding, which provides the message meaning identification for the student and implies an opposite process - recognizing, decoding.

M.A. Kholodnaya notes that there are four means of information coding (and consequently, four modalities of experience) in informational exchange between a person and the surrounding world: verbally-speech (as signs), visualspatial (as images), object-practical (as locomotive actions) and sensory-emotional (as feelings and emotions) (Kholodnaya, M.A. (2002)).

Furthermore, the main way of information coding in situation of learning-teaching geometry is the visual-spatial mean (as images). As noted by the psychologists, the development of geometric knowledge system appears as a result of the development of an integral mental system "perception image - concept". The stages of its development may be schematically presented the following way (Gusev, V.A., Orlov, V.V., Panchishina, V.A. et al. (Ed. Gusev, V.A.) (2004)): the first block (level of representations): perception image - representation - generalized representation or pre-concept (image-concept); the second block (verbally-logical level): concept - system of concepts.

The term "pre-concept", according to L.S. Vygotskiy (Vygotskiy, L.S. (1984)), was widely used in the 1930s in pedology. Pre-concept is defined as image-concept or a concept, which has a simple and direct relation to an object and is not included in the system of a concept of a higher level. According to Vygotskiy, pre-concept is the main mental structure of the elementary school children (6-11 years old). The development of pre-concept is related to the activation of imaginative thinking, the activation of so-called "sign naturalization of geometric concept" (Ustilovskaya, A.A. (2008)) and "prepares" the concept, which is related to the functioning of verbally-logical (conceptual) thinking.

We will proceed from the known fact that geometric concepts learning implies the knowledge of the means to interpret ideal objects in a physically real space ("naturalization of geometric drawing") and, at the same time, the understanding of physical bodies (objects) limitations in geometric objects interpretation. On the one hand, according to G.D. Geyzer (Gleyzer, G.D. (1978)), if you do not provide a student with an opportunity of objective manipulations with figures, he will memorize the texts without understanding them. On the other hand, the goal of teaching geometry is to develop an ideal reality itself and create a special understanding and manipulating figures. It is therefore important to note that in the studies by E.N. Kabanova-Meller, N.F. Talyzina, etc. it is stated that the phenomenon of sign naturalization of geometric concept has a negative impact on the process of learning the geometric concepts as theoretical ones. The reason for this lies in the fact that the condition of transitioning to the theoretical level of geometric thinking is overcoming the sigh naturalization - the creation of Euclidian geometry space as a space, pre-defined by specific characteristics, not common for the real, natural world (Ustilovskaya, A.A. (2008)).

\subsection{Stages of communication and translation of axiological content of geometric concepts learning activity}

We will distinguish geometric objects, on the one hand, and geometric concepts, i.e. the concepts of geometric objects, which a student has, on the other. Geometric objects are points, lines, figures, surfaces, bodies, etc., their elements and configurations of elements. Geometric concept captures the process of reconstruction (reproduction) of the object in the mind, which may not repeat the sequence of its appearance in theory. The basis of geometric concepts contains of preconcepts - object-oriented actions with objects, however, concepts learning does not only consist of perception image, sensory perception, action and empiric generalization.

Thus, the communication in geometry learning situation, which implies the development of understanding and means of operating with geometric concepts, proceeds in two stages. The content of these stages is determined by the activity component structure in geometric concepts, which includes object-oriented actions, implemented on the objects, as well as operations, which are not implemented on the objects.

The first stage (which corresponds with the level of representation) consists of naturalization of ideal geometric concept content in a sign as a way to overcome formalism; a perception image is created. Supposedly, the students learn object-oriented actions with figures-objects, such as drawing, constructing and deformation. This type of actions teaches the direct perception of the drawing, i.e. naturalization of knowledge appears and everything leads to objects - it materializes, which, strictly speaking, is incorrect for geometry. As A.A. Ustilovskaya states, any materialization of an ideal object becomes not an ideal object but a thing. Because geometric objects are not things, it is impossible to take material actions towards them (Ustilovskaya, A.A. (2008)).

During the second stage a pre-concept - image-concept (the level of representations) - and a concept (verbally- 
logical level) develop. For this level it is necessary to overcome the sign naturalization - it is a process of so-called denaturalization, which is provided, among other factors, by psychologically-didactical algorithms of awareness, understanding and generalizing activity content and process. Geometric concepts are not abstractions, obtained as a result of empirical generalization (G.P. Schedrovitskiy). Consequently, operating with geometric concepts cannot be derived from object-oriented actions. Another type of operation - integral operations, not limited to actions - is necessary.

In order to provide operational way of geometric figures images perception it is meaningful to use the multimediabased lections-presentations, developed by us, which allow dynamically interpreting of model representations of the objects and connections between them. Moreover, mental representations of imagined geometric object, which is captured in the image as in a symbolic sign, is provided by sequential development of representations "from topologic to metric through projective".

We present a diagram of the geometric concepts axiological content learning (figure 1).

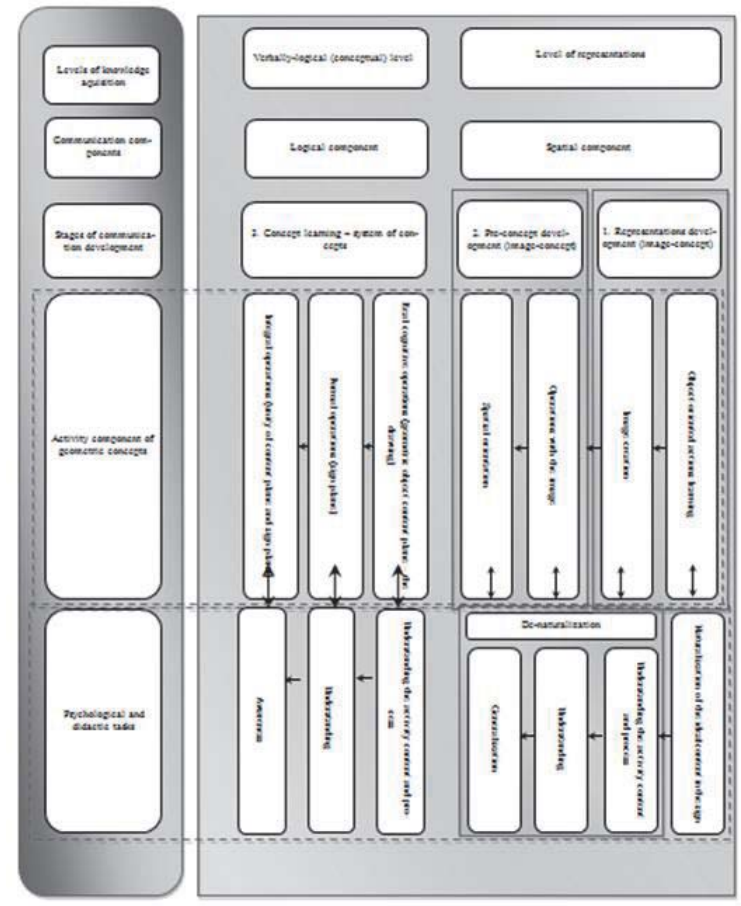

1. Motivation for learning geometry material, which provides the mechanisms of functioning of such stages, as axiological orientation and impulse (Podaeva, N.G., Podaev, M.V. (2013)).

2. Spatial component of communication (level of representations)

1) Perception image - representation. The naturalization of an ideal content in the sign as a way of overcoming the formalism. A student is already familiar with the signs of the learned figures, so this stage creates the conditions for understanding the sole ideal geometric model, captured in the drawing. This is the creation of the image: materialization, representation in a material model, 3-dimensional computer modelling. This level implies the learning of object-oriented actions with figures-objects, such as drawing, constructing, deformation, etc.

2) Generalized representation or pre-concept (image-concept). Overcoming sign naturalization - so-called de-naturalization, provided by psychological and didactic tasks of awareness, understanding and generalizing of activity content and process. Development of topologic representations of the studied geometric object: understanding of the symbolic function of the drawing and mastering the means of operating with the drawing as with a complex semiotic object (operating with an image, spatial orientation).

3. Logical component of communication (verbally-logical level). Concept - system of concepts. Development of 
geometric concepts as theoretical ones: defining metric qualities, which are significant for understanding the studied geometric object; establishing a connection between topologic and metric qualities. Defining a concept, which has these qualities as a maximal sub-system, and a concept, which has them as the most common ones. Furthermore, the range of geometric object's significant qualities is divided into a range of essential and sufficient qualities (presumably, there would be more than one of such ranges) and a concept definition is stated. This stage of geometric concepts development as theoretical ones requires moving from concept content, which presents in the communication with an adult, to student's efforts to capture this content by "modelling" it with the help of manipulating the drawing.

\subsection{Logical component of communications. Patterns of geometric concepts development}

We will define the meaning of the logical component of communication on the example of teaching geometry to younger adolescents. As noted by the psychologists, during this age, despite dominating visually-imaginative way of thinking, there is a transfer to abstract and logical thinking. The students begin to place hypotheses, explore and compare the alternatives while solving similar tasks, etc. It is especially necessary for this age to have a stage in education, which provides the introduction of correct logical structures establishment and learning of concepts, such as geometric ones.

As the units of integral thinking process G.P. Schedrovitskiy proposes integral operations, which include real cognitive operations (with objective content) and formal operations, which provides the unity of content plane (the plane of geometric object) and sign representation plane (Schedrovitskiy, G.P. (1995)). Real operations, which have cognitive nature, begin directly from the object, they include actions with the object and can subtract a certain content from the object.

Formal operations begin from the provided knowledge, language expressions, which capture "knowledge connection" and allow to transfer from one object quality to another, but which are not related to searching for a new content in the object, i.e. play the role of cognitive operations while not being them. Tre result of conducting integral operations, which register in the conscience as images, is the appearance of new knowledge and knowledge connections. Such images reflect the process of obtaining knowledge itself and capture the object, meaningful and formal operations and knowledge connections. On the high level of geometric thinking development integral operations are folded and are presented as images during thinking; these images allow to "unfold" the information and restore the process of obtaining certain knowledge, if necessary (Schedrovitskiy, G.P. (1995)).

Thus, we will further consider the following statements, which are the basis of communication concept of the verbally-logical (conceptual) level.

It is necessary to distinguish between geometric knowledge as such (geometric concept content plane) and its translation (sigh representation plane). Geometric knowledge, as any other, exists in the processes of "creating" and "using" (real cognitive operations, according to Schedrovitskiy), while the sign representation is a deductive presentation of the already obtained results (formal operations, which are not cognitive).

The units of geometric thinking - integral operations - include real cognitive and formal operations, which provides the unity of content plane (objects plane) and sign representation plane.

\section{Results}

Based on the theoretical statements about communication development patterns, during a developmental study we created teaching materials for $5-6^{\text {th }}$ grades students of the secondary schools. This materials include an educational textbook in introductory course "Fundamentals of geometry", which requires one hour weekly and has been integrated in the curriculum as an educational component.

During experimental learning we defined three stages the logical component of communication structure. The content of these stages is defined by the classification of studied geometric concepts based on the level of thinking process operations (real, formal and integral operations).

\subsection{The level of real cognitive operations}

The first stage, which corresponds with the level of real cognitive operations and is provided by realization of psychological and didactic pattern of awareness, operates with the concepts, which can be nominally divided into two groups. The first group contains of the concepts based on students' life experience. These concepts belong to the lowest level of logical structure. They are ideal empirical objects, which are brief models of real world. During this stage we can 
talk about real cognitive operations of the thinking process, which begin directly from the object, contain of actions with the object and can subtract certain content from the object. This level often contains only of a geometric concept representation (pre-concept - image-concept); there is no definition from the closest related concepts or typical differences. Examples of such concepts are vertical and adjacent angles, opposing half-lines, polygonal surface, cube, rectangular or slanted parallelepiped and prism, pyramid, etc.

We present an example of introducing the concepts of vertical and adjacent angles. Firstly, the students are proposed to draw two intersecting lines and to find all of the angles they create (pic. 2).

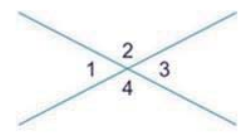

Pic. 2. Intersecting lines

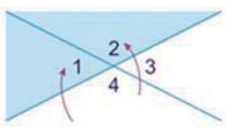

Adjacent angles

Pic. 3. Adjacent angles.

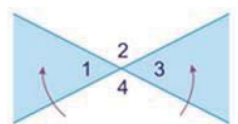

Vertical angles

Pic. 4. Vertical angles.

Then we draw the students' attention to the angles 1 and 2. We remind them of a straight angle and make a conclusion about their sum - it equals $180^{\circ}$. Then we say that the angles 1 and 2 , which are lying next to each other, are called adjacent angles (pic. 3). The sum of two adjacent angles equals $180^{\circ}$. In order to clarify the concept of "adjacent" we refer to an abstract from a definition dictionary: the word "adjacent" means being placed along something, adjoining something.

Introducing the concept of vertical angles may be conducted the following way. We propose a number of tasks:

1) Find all angles, adjacent to $\angle 2$ (pic. 4).

2) Calculate the following sums:

$\angle 2+\angle 3=$ ?

$\angle 4+\angle 3=?$.

3) What can you conclude about angles 2 and 4 ?

We furthermore state that angles 2 and 4, lying opposite each other, are called vertical angles. We suggest finding the other pair of vertical angles. Then we articulate the quality of vertical angles: they are equal.

During introduction of the concepts from the second group we also mostly refer to the students' empirical knowledge, however, in this case there is a "transfer from the objects to the model drawings", the students receive unobvious concepts of geometric figure, square surface of a flat figure, volume, etc.

For example, before introducing the concept of geometric figure we present a short historical discourse and then propose a problem: "what does geometry study?".

In order to answer that question we model the following situation: imagine that we have to build a table. Multiple questions appear: which material should we use; which size; how should the surface and the legs of the table look; which color should it be?

We then clarify: which shape can the table top have; how can the table legs be placed from one another; which shape can the table legs have; which size should it be?

Then we draw the students' attention to the fact that we discussed only the shape and size of the table and mutual location of its part. We conclude that the material and the color do not matter in geometry - it "abstracts" from them. Geometry studies only shape and size of the object. Moreover, it studies not the objects themselves but so-called "geometric figures".

We discuss a football as an example. We disregard the color and the material it was made from and obtain a geometric figure called "a ball".

Then we note such characteristic of geometric figures as being abstract, we say that they exist only in our imagination and our thoughts. We can now define a geometric figure: "Geometric figure is a mental image of an object, which lacks all qualities of an object, apart from shape, sizes and mutual location of its details".

This example vividly demonstrates that, prior to defining the concept of a geometric figure, we studied separate qualities, which are present in the definition, on the empirical level. These qualities are: mental image, mutual location of the parts (topological representation - perception image), shape, size (projective and metric qualities). None of these qualities were studied before, so it is impossible to talk about presenting this topic on a deductive basis, however, these qualities are not very complex and they should be intuitively clear for the students. 
It is necessary to point out that, despite the lack of logical structure of the material presentation, the concepts from the first two groups are never presented on the empirical level only.

\subsection{The level of formal cognitive operations}

The second stage of communication and translation of young adolescents' activity of learning the axiological content of geometric concepts is provided by psychological and didactic task of understanding and implies a higher level of logical organization of the material. This stage requires formal cognitive operations, which begin from "provided" knowledge and language expressions, which capture "knowledge connections", thus allowing moving from one quality of the object to another.

In this case, the proposed definitions are relatively formal; however, not all of the concepts and qualities in them have been previously introduced.

For example, during the definition of half-line, segment, circle, polyhedron we use the concept of "boundedness" (of the line, surface or space), which was not defined before. Here we address the students' intuitive representation of the limited amount of topologic varieties.

Let us illustrate an introduction of a concept of "simple polyhedron". First we remind the students how we defined a segment: it is a part of the line, which is constrained from two ends by the points, which are the ends of the segment. We set a similar problem: how can we constrain a surface? On the previous lessons an answer to this question led the students to the polygon. So we propose a similar problem: what can we use to constrain a part of the space? By parts of the surface - polygons. At this point we come to the definition of the concept of polyhedron: "Polyhedron is a part of the space, constrained by polygons at each side".

\subsection{The level of integral operations}

On the third stage (psychological and didactic task of generalization) the definitions of the concepts of line, polygon, parallel and intersecting lines use only those concepts and qualities that have been introduced before. Here we talk about developing the units of geometric thinking (G.P. Schedrovitskiy) - of integral operations, which include real and formal operations that provide the unity of content plane (plane of the drawing - real operations) and sign plane (deductive thoughts - formal operations).

Integral operations become folded and are presented as images during the process of thinking; these images allow "unfolding" the necessary operation and reconstruct the process of obtaining certain knowledge, if required.

We will present introduction of a concept of a line. Firstly, we introduce an intermediate concept of a simplest line, which belongs to the first group: like a plane, which "draws" a line in the sky as a result of moving, we can draw a line by smoothly moving a pencil on a paper (without lifting it from the page).

The lines in pic. 5 are called "the simplest lines". They do not "auto-intersect" or "close".

Then we state that we can combine other, more complex lines from the simplest ones (pic. 5). We demonstrate it on the examples and give the definition of the concept itself: a line is a figure, which can be combined form the simplest lines (in geometry a line is a figure in three-dimensional Euclidian space, which can be covered by not more than a countable amount of simplest lines).

We accompany this definition by a historical reference to the origin of the term: line - from Latin "linum" - means "flax (linen) string". Ancient Greek geometry scientist Euclid sayd: a point is something that does not have parts; a line is a length without width.
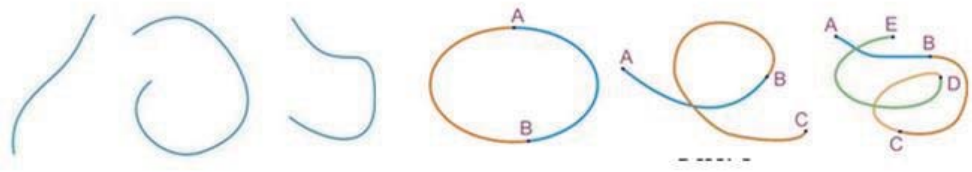

Pic. 5. Ex am ples of lines

\section{Conclusion}

This article presents an essential characteristic of the concept of communication as a stage of social and cultural 
dynamics in axiological learning in the situation of studying geometry (Podaeva, N.G. (2012)). The core basis is a framework, which describes a vector of communication development as connecting three planes (coordinates). The first one is "movement" in the plane of social and cultural content of learning. The second coordinate describes the "movement" in psychological and didactic context. The third coordinate is the "movement" in the plane of learning the activity component of geometric concepts and their axiological content (meaning).

We describe a diagram of the organization of geometric concepts axiological content learning in the process of communication. We study the content of each stage of the development of spatial and logical components of communication on the example of teaching geometry to younger adolescents.

We validated and experimentally confirmed a following hypothesis: social and communicative processes efficiency in the situation of geometry learning in younger adolescents depends on multiple factors, such as realization of psychological and didactic patterns of awareness, understanding and generalizing activity content and process; gradual development of the activity of learning geometric concepts value content; gradual development of an integral psychological structure "image - representation - pre-concept - concept - system of concepts"; gradual development of geometric concepts activity components - object-oriented actions, real cognitive operations, formal operations.

Perspectives in further studying of the problem of the geometric concepts learning activity development require noting the following psychological and didactic patterns of the concepts development process in younger adolescents:

- development of the main components of conceptual mental structures (means of information encoding, semantic structures, concepts characteristics);

- development of declarative, procedural and evaluative knowledge;

- gradual development of subjective image of the concept content: impulse, categorization, transfer, folding.

\section{Acknowledgements}

The study is funded by Russian Humanitarian Science Foundation, project \# 14-16-48007 "The update of school mathematics education content: social and cultural approach".

\section{References}

Dobrenkov, V.I., Nechaev, V.Ya. (2003). Obschestvo i obrazovanie. M.: INFRA-M.

Gerasimova, E. Investitsii v uchiteley vsegda samye vygodnye. Nezavisimaya gazeta. Retrieved from http://www.ng.ru/education/201312-17/8_teachers.html.

Gleyzer, G.D. (1978). Razvitie prostranstvennyh predstavleniy shkolnikov pri obuchenii geometrii [Tekst]: nauch.issled. institut obschego obrazovaniya vzroslyh Akademii ped. nauk SSSR. M.: Pedagogika.

Gusev, V.A. (2003). Psihologo-pedagogicheskie osnovy obucheniya matematike. M.: Verbum-M.

Gusev, V.A. (2010). Teoreticheskie osnovy obucheniya matematike v sredney shkole. Psihologiya matematicheskogo obrazovaniya. M.: Drofa.

Gusev, V.A., Orlov, V.V., Panchishina, V.A. et al. (Ed. Gusev, V.A.) (2004). Metodika obucheniya geometrii: uchebnoe posobie dlya stud. vyssh. ped. ucheb. zavedeniy. M.: Akademiya.

Kabanova-Meller, E.N. (1962). Psihologiya formirovaniya znaniy i navykov u shkolnikov. M.: Izd-vo APN RSFSR.

Kholodnaya, M.A. (2002). Psikhologiya intellekta. Paradoksy issledovaniya. SPb.: Piter, 264 p.

Podaeva, N.G. (2012). Sotsiokulturnaya kontseptsiya matematicheskogo obrazovaniya. Elets: EGU im. I.A. Bunina.

Podaeva, N.G., Podaev, M.V. (2013). Sotsiokulturnoe soderzhanie shkolnogo matematicheskogo obrazovaniya: mysledeyatelnostnye tekhnologii. The Emissia. Offline Letters: elektronnyy nauchnyy zhurnal, Retrieved from http://www.emissia.org/offline/2013/ 1948.htm.

Podhodova, N.S. (1999). Teoreticheskie osnovy postroeniya kursa geometrii 1-6 klassov: Diss. ... d-ra ped. nauk: 13.00.02. SPb.

Ryzhik, V. (2005). Vremya razbrasyvat kamni? Matematika, prilozhenie k "PS", 11.

Sarantsev, G.I. (2000). Obuchenie matematicheskim dokazatelstvam v shkole: Kn. dlya uchtelya. M.: Prosveschenie.

Savitskaya, N. Urok matematiki PISA. Nezavisimaya gazeta. Retrieved from http://www.ng.ru/education/2014-01-21/8_pisa.html/.

Schedrovitskiy, G.P. (1995). Izbrannye trudy. M.: Shk.Kult.Polit., 800 p.

Schedrovitskiy, G.P. Zametki k opredeleniyu ponyatiy "myshlenie" i "ponimanie". Retrieved from http://www.fondgp.ru/gp/biblio/rus/67.

Tsukar, A.Ya. (1999). Metodicheskie osnovy obucheniya matematike $v$ sredney shkole $s$ ispolzovaniem obraznogo myshleniya: diss. ...d-ra ped. nauk: 13.00.02. Novosibirsk, $430 \mathrm{p}$.

Ustilovskaya, A.A. (2008). Psihologicheskie mekhanizmy preodoleniya znakovoy naturalizatsii idealnogo soderzhaniya geometricheskikh ponyatiy: diss. ...kand. psihol. nauk. M., $160 \mathrm{p}$.

Vygotskiy, L.S. (1982). Sobranie sochineniy: V 6 t. T. 2: Myshlenie i rech. M.: Pedagogika.

Vygotskiy, L.S. (1984). Sobranie sochineniy: V 6 t. T. 4: Detskaya psihologiya. M.: Pedagogika.

Yakimnaskaya, I.S. (1980). Razvitie prostranstvennogo myshleniya shkolnikov: monografiya. M.: Pedagogika. 